\title{
The Poison Pen: Bedside Diagnosis of Urinary Diquat
}

\author{
Rais Vohra • Anthony Salazar • F. L. Cantrell • \\ Ravindra Fernando $\cdot$ Richard F. Clark
}

Published online: 13 March 2010

(C) The Author(s) 2010. This article is published with open access at Springerlink.com

\begin{abstract}
Diquat is a bipyridyl herbicide with nephrotoxic effects. This in vitro study demonstrates a colorimetric test for detection of diquat in human urine. Urine specimens using ten concentrations of diquat herbicide solution and controls for urine and glyphosate were prepared. A two-step assay (addition of bicarbonate followed by sodium dithionite) was performed, with a resulting color change of the original solution for each specimen. Color change intensity was noted immediately and after $30 \mathrm{~min}$, by gross visual inspection. A green color with concentration-dependent intensity was detected in all specimens, in which concentrations of diquat solution ranged from 0.73 to $730 \mathrm{mg} / \mathrm{L}$. This colorimetric effect disappeared after $30 \mathrm{~min}$. The sodium bicarbonate/dithionite test may be useful as a qualitative bedside technique for the detection of urinary diquat in the appropriate clinical setting.
\end{abstract}

Presentation Information The preliminary findings of this study were presented as a poster at the Annual Congress of European Association of Poison Control Centers, Athens, Greece 2007. All photos are owned by Rais Vohra, MD (first author and corresponding author).

\section{R. Vohra $(\triangle)$}

Department of Emergency Medicine,

UCSF-Fresno Medical Center,

155 N. Fresno Drive,

Fresno, CA 93701, USA

e-mail: raisvohra@hotmail.com

A. Salazar · R. F. Clark

University of California,

San Diego, CA, USA

F. L. Cantrell

California Poison Control System,

San Diego, CA, USA

R. Fernando

National Hospital,

Colombo, Sri Lanka
Keywords Diquat $\cdot$ Herbicide toxicity $\cdot$ Bedside diagnosis

Dear Editor of the Journal of Medical Toxicology,

The bipyridyl compounds paraquat and diquat can cause severe toxicity following ingestion [1]. These compounds are popular herbicides because of their relatively low cost, rapid action, and environmental safety. Paraquat causes local tissue irritation/erosion followed by renal dysfunction and severe, delayed pulmonary toxicity [2]. While diquat shares the corrosive and nephrotoxic properties of paraquat, it lacks the direct pulmonary toxicity [3]. Because of their widespread availability throughout the world, human poisonings with these compounds remain a problem. We would like to share our demonstration of a colorimetric bedside test which can qualitatively detect diquat and other bipyridyl compounds in human urine. Although this technique has been previously described in the setting of paraquat exposure, we feel that it is worth revisiting as an example of a rapid bedside diagnostic technique available to the clinical toxicologist even in resource-limited settings.

We obtained Roundup Herbicide Weed and Grass Killer $^{(8)}$ whose active ingredients are diquat dibromide $(0.73 \%)$ and glyphosate $(18 \%)$ in addition to three samples (A, B, and C) of human urine. Quantities of diquatcontaining solution were added to the urine specimens to yield three sets $(\mathrm{A}, \mathrm{B}$, and $\mathrm{C})$ of ten different concentrations of diquat: $730,365,219,73,51.1,36.5,21.9,7.3,3.65$, and $0.73 \mathrm{mg} / \mathrm{L}$ in a total volume of $10 \mathrm{~mL}$ (Fig. 1). Samples of unadulterated urine served as negative control specimens and Roundup Herbicide ${ }^{\circledR}$ with only glyphosate $(2 \%)$ was diluted 1:1 v/v with each urine sample (A, B, and $\mathrm{C}$ ) to control for the effect of glyphosate.

Sodium bicarbonate $(1 \mathrm{~g})$ was added to each specimen followed 2 min later by sodium dithionite powder $(1 \mathrm{~g})$. A green color with dose-dependent intensity was detected in all of the diquat-containing specimens, but not in the urine- 


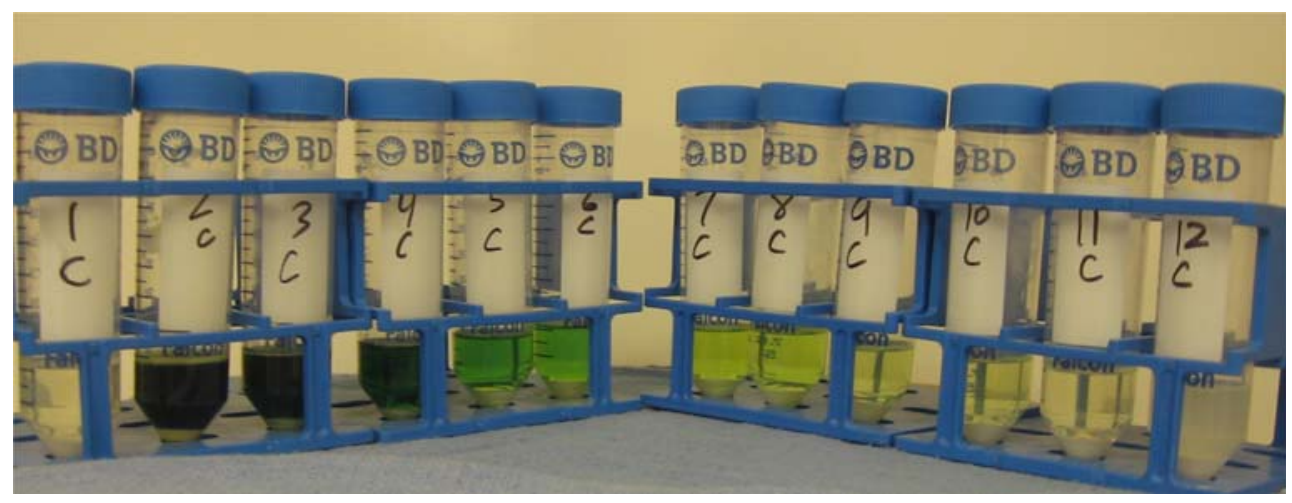

Fig. 1 Addition of sodium bicarbonate and sodium dithionite to urine specimens containing decreasing concentrations of diquat. This picture was taken immediately after the addition of dithionite to one of three sets of specimens. (Set $C$ is pictured here; similar results in dose-dependent color change were noted with the other sets, $A$ and $B$ ).

and glyphosate-only controls. This green tint was transient and faded after approximately $30 \mathrm{~min}$.

We share our in vitro demonstration of this qualitative technique as an example of bedside testing for the bipyridyl herbicides. In situations where quantitative testing is not readily available and the diagnosis of bipyridyl herbicide poisoning is suspected, the use of this simple test may aid in rapidly confirming the diagnosis of exposure. As previously described, a blue-purple color change indicates the presence of paraquat, while a green color change, as in the present study, indicates the presence of diquat.

It should be noted that, in the clinical setting, very low concentrations of urinary diquat would limit the sensitivity of this diagnostic test method. For example, one in vivo study in which rats were given oral doses of diquat dibromide (5 or $10 \mathrm{mg} / \mathrm{kg}$ ) demonstrated that only $4 \%$ to $11 \%$ of the total diquat dose is actually excreted in the urine and that this excretion occurred within 24 to $48 \mathrm{~h}$ [4]. Thus, the colorimetric detection test is likely to be useful only if done within the first few hours of a large-dose ingestion and preferably with the first urine voided after exposure to diquat.

Limitations to the present study include the in vitro design, subjective visual evaluation of the assay results, small sample size, and urinary concentrations of herbicide beyond the range expected clinically. Additional investigations, using samples from diquat-poisoned patients, would
Each number represents decreasing concentrations of diquat or control as follows: 1 -urine only, 2-730 mg/L, 3-365 mg/L, 4-219 mg/L, $5-73 \mathrm{mg} / \mathrm{L}, 6-51.1 \mathrm{mg} / \mathrm{L}, 7-36.5 \mathrm{mg} / \mathrm{L}, 8-21.9 \mathrm{mg} / \mathrm{L}$, 9$7.3 \mathrm{mg} / \mathrm{L}, 10-3.65 \mathrm{mg} / \mathrm{L}, 11-0.73 \mathrm{mg} / \mathrm{L}$, and 12 - glyphosate-only herbicide solution

confirm or clarify the clinical utility of this colorimetric test, especially at the low concentrations typically found in urine after exposure.

Conflict of Interest Syngenta Pharmaceuticals (UK) provided the sodium bicarbonate and sodium dithionite reagent powders used in this study. The authors received no financial support for this work and have no conflicts of interest.

Open Access This article is distributed under the terms of the Creative Commons Attribution Noncommercial License which permits any noncommercial use, distribution, and reproduction in any medium, provided the original author(s) and source are credited.

\section{References}

1. Braithwaite RA (1987) Emergency analysis of paraquat in biological fluids. Human Toxicol 6(1):83-86

2. Dinis-Oliveira RJ, Duarte JA, Sánchez-Navarro A, Remião F, Bastos ML, Carvalho F (2008) Paraquat poisoning: mechanisms of lung toxicity, clinical features, and treatment. Crit Rev Toxicol 38(1):13-71

3. Jones GM, Vale JA (2000) Mechanisms of toxicity, clinical features, and management of diquat poisoning: a review. J Toxicol Clin Toxicol 38(2):123-128

4. Daniel JW, Gage JC (1966) Absorption and excretion of diquat and paraquat in rats. Br J Ind Med 23:133-136 